\title{
A nomogram to predict lymph node metastasis risk for early esophageal squamous cell carcinoma
}

\author{
Xiaofeng Duan ${ }^{* \dagger}$, Xiaobin Shang ${ }^{\dagger}$, Jie Yue ${ }^{\dagger}$, Zhao Ma, Chuangui Chen, Peng Tang, Hongjing Jiang ${ }^{*}$ and \\ Zhentao Yu*
}

\begin{abstract}
Background: A nomogram was developed to predict lymph node metastasis (LNM) for patients with early-stage esophageal squamous cell carcinoma (ESCC).

Methods: We used the clinical data of ESCC patients with pathological T1 stage disease who underwent surgery from January 2011 to June 2018 to develop a nomogram model. Multivariable logistic regression was used to confirm the risk factors for variable selection. The risk of LNM was stratified based on the nomogram model. The nomogram was validated by an independent cohort which included early ESCC patients underwent esophagectomy between July 2018 and December 2019.

Results: Of the 223 patients, 36 (16.1\%) patients had LNM. The following three variables were confirmed as LNM risk factors and were included in the nomogram model: tumor differentiation (odds ratio $[O R]=3.776,95 \%$ confidence interval $[\mathrm{Cl}] 1.515-9.360, p=0.004)$, depth of tumor invasion $(\mathrm{OR}=3.124,95 \% \mathrm{Cl} 1.146-8.511, p=0.026)$, and tumor size $(\mathrm{OR}=2.420,95 \% \mathrm{Cl} 1.070-5.473, p=0.034)$. The $\mathrm{C}$-index was 0.810 (95\% Cl $0.742-0.895)$ in the derivation cohort (223 patients) and 0.830 (95\% Cl 0.763-0.902) in the validation cohort (80 patients).

Conclusions: A validated nomogram can predict the risk of LNM via risk stratification. It could be used to assist in the decision-making process to determine which patients should undergo esophagectomy and for which patients with a low risk of LNM, curative endoscopic resection would be sufficient.
\end{abstract}

Keywords: Esophagus, Cancer, Lymph nodes, Metastasis, Nomogram model

\section{Background}

Esophageal squamous cell carcinoma (SCC) is the most common pathological type in China [1]. Surgery after neoadjuvant therapy is the main treatment method with curative potential for early- or advanced-stage disease. Although the incidence of mortality and complication after esophageal surgery have decreased significantly in

\footnotetext{
* Correspondence: suaveduan@yahoo.com; xduan@tmu.edu.cn; yuzhtao@hotmail.com

${ }^{+}$Xiaofeng Duan, Xiaobin Shang and Jie Yue contributed equally to this work. Department of Esophageal Surgery, Tianjin Medical University Cancer Hospital and Institute, Key Laboratory of Cancer Prevention and Therapy, National Clinical Research Center for Cancer, Tianjin 300060, China
}

some high-volume cancer centers, esophagectomy can seriously affect the quality of life. To maintain the integrity of the esophagus and reduce the morbidity and mortality of the procedure, endoscopic resection has gradually become the treatment option for some patients with early-stage esophageal cancer [2]. Endoscopic resection, however, may not be curative and has several issues, including tumor residue; without lymph node dissection, it can lead to local recurrence and tumor spread. For patients with lymph node metastasis (LNM), radical lymph node dissection is crucial to decrease disease recurrence and prolong survival.

C C The Author(s). 2021 Open Access This article is licensed under a Creative Commons Attribution 4.0 International License, which permits use, sharing, adaptation, distribution and reproduction in any medium or format, as long as you give appropriate credit to the original author(s) and the source, provide a link to the Creative Commons licence, and indicate if changes were made. The images or other third party material in this article are included in the article's Creative Commons licence, unless indicated otherwise in a credit line to the material. If material is not included in the article's Creative Commons licence and your intended use is not permitted by statutory regulation or exceeds the permitted use, you will need to obtain permission directly from the copyright holder. To view a copy of this licence, visit http://creativecommons.org/licenses/by/4.0/ The Creative Commons Public Domain Dedication waiver (http://creativecommons.org/publicdomain/zero/1.0/) applies to the data made available in this article, unless otherwise stated in a credit line to the data. 
However, the incidence of LNM in patients with earlystage esophageal cancer is relatively high, especially for submucosal infiltrating tumors [3-8]. The LNM rate in T1a stage esophageal SCC (ESCC) patients is $0-15.4 \%$ and that in T1b stage ESCC patients is 15-51\% [3-11]. Clinical staging currently relies on endoscopic ultrasound and positron emission tomography (PET) computed tomography (CT), but the limitations of these techniques do not allow for preoperative accurate detection of all LNMs [12-14]. In the JCOG0502 study, LNM occurred in $27 \%$ early-stage cases, as determined by pathological examinations [15]. Therefore, it is crucial to identify the risk factors of LNM for early esophageal cancer to aid in the decision-making process of the surgical procedure and treatment strategy. In this study, a nomogram model was developed and validated by another cohort to predict LNM and determine the surgical management strategy based on risk stratification in patients with early-stage ESCC.

\section{Methods}

\section{Database}

Data on consecutive esophageal cancer patients at our cancer center between January 2011 and June 2018 were obtained from our retrospective database. Histopathology confirmed that 300 patients had pT1 stage esophageal cancer. Patients who underwent neoadjuvant therapy $(n=13)$, those with non-SCC $(n=14)$, and those who underwent primary endoscopic resection $(n=50)$ were excluded. Finally, a total of 223 patients were included in the present study, including $82 \mathrm{pT} 1 \mathrm{a}$ and 141 pT1b patients. The study flow chart is shown in Fig. 1. These patients were included as the derived cohort.
Another case cohort, later used as the validation cohort, included 80 patients who underwent esophagectomy between July 2018 and December 2019. Patients with the same inclusion and exclusion criteria as those in the derived cohort at the same cancer center were also identified.

Our study cohort was classified according to the seventh edition of the AJCC/UICC TNM classification of malignant tumors [16].

\section{Preoperative evaluation}

Preoperative evaluation included physical examination, laboratory analysis, imaging examination and endoscopy. The diagnosis and staging of esophageal cancer were performed using endoscopic biopsy and endosonography. Ultrasound and CT combined with enhanced scanning determined local growth, lymph node status, and distant metastasis. In some cases, PET-CT was used to exclude metastatic diseases and evaluate tumor resectability.

\section{Surgical procedure}

All patients included in this study underwent transthoracic esophagectomy with two- or three-field lymphadenectomy. For patients with upper esophageal cancer or suspicions LNM on preoperative examination, threefield lymphadenectomy was performed. For patients with middle/lower esophageal cancer and without suspicions LNM, two-field lymphadenectomy was performed. Most patients underwent minimally invasive esophagectomy (video/robot-assisted Ivor-Lewis or McKeown procedures). Open surgery was performed for some patients.

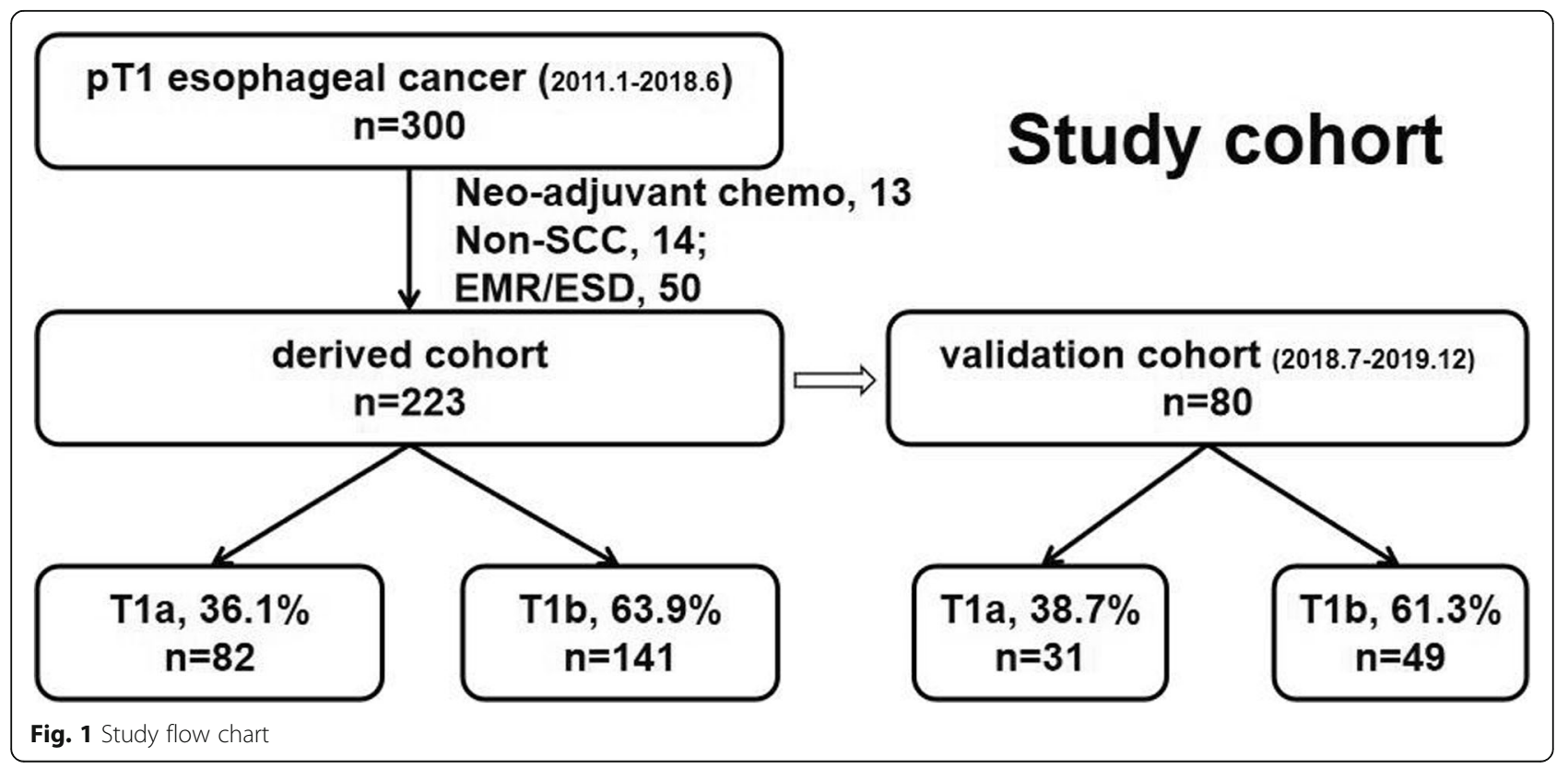


The detailed surgical procedure could be found in our previous study [10].

\section{Statistical analysis}

We used the statistical software package $\mathrm{R}$ (version 3.0.0, $\mathrm{R}$ Foundation for statistical calculations) and SPSS Statistics (version 18.0, SPSS Inc., Chicago, IL) for statistical analysis. Univariate analysis was performed using the $\mathrm{x} 2$ test or Fisher's exact test. Binary logistic regression analysis was used to investigate the LNM risk factors. Clinicopathological variables with a $P$ value of $<0.01$ in univariate analysis were included in the logistic regression analysis (two-sided and $P<$ 0.05 was considered significant). In this study, the receiver operating characteristic (ROC) curve and Youden index were used to determine the optimal cutoff point for the continuous variables in the LNM prediction [17].

To test the LNM prediction ability for each risk factor and for comprehensive analysis, a ROC curve was constructed and the area under the curve (AUC) was considered an estimation of the prediction accuracy [17]. A nomogram model was constructed based on the parameters related to LNM in multivariate analysis.

\section{Results}

\section{Patients' characteristics}

A total of 223 patients were used as the derivation cohort. The demographic and clinical characteristics of the patients are presented in Table 1 . Overall, 36 patients had LNM, and the LNM rate was $16.1 \%$. Of the 36 patients with LNM, 30 had $\mathrm{pN} 1$ disease, six had pN2 disease, and none had pN3 disease. The detailed LNM information is shown in Table 2.

\section{LNM risk factors}

Univariate and multivariate logistic regression analysis were performed to identify the risk factors significantly associated with LNM (Table 3). Three variables were confirmed as independent LNM risk factors: tumor differentiation (odds ratio $[\mathrm{OR}]=3.776,95 \%$ confidence interval $[\mathrm{CI}] 1.515-9.360, p=0.004)$, depth of tumor invasion $(\mathrm{OR}=3.124,95 \% \mathrm{CI} 1.146-8.511, p=0.026)$, and tumor size $(\mathrm{OR}=2.420,95 \% \mathrm{CI} 1.070-5.473, p=0.034)$.

\section{Nomogram model}

We built a nomogram that incorporated LNM risk factors confirmed by logistic regression analysis. The prediction ability of the three risk factors were: tumor differentiation $(0.617,95 \%$ CI $0.509-0.724)$, depth of tumor invasion $(0.623,95 \%$ CI $0.532-0.714)$, and tumor size (0.596, 95\% CI 0.494-0.697). The C-index was 0.810 (95\% CI 0.742-0.895) (Fig. 2a).
This compiled nomogram allowed for the estimation of the risk of LNM for each patient. It also illustrated the contribution of each risk factor to the overall LNM risk. The clinical use of the nomogram is illustrated in Fig. 3.

\section{Validation cohort}

A total of 80 patients were used as the validation cohort. The demographic and clinical characteristics of the patients are summarized in Table 1 . A total of 13 patients had LNM, and the LNM rate was $16.3 \%$.

Consistent with the derivation cohort, tumor differentiation $(\mathrm{OR}=3.902,95 \%$ CI $1.843-10.354, p=0.005)$, depth of tumor invasion $(\mathrm{OR}=3.234,95 \%$ CI 1.230 8.543, $p=0.010)$, and tumor size $(\mathrm{OR}=2.674,95 \% \mathrm{CI}$ 1.876-6.320, $p=0.008$ ) were confirmed as independent risk factors associated with LNM (Table 4). The C-index was 0.830 (95\% CI 0.763-0.902) (Fig. 2b).

\section{LNM risk stratification}

Based on our nomogram model we constructed, the risk of LNM was stratified into different intensities starting from zero for cases with well-differentiated T1a-stage tumors measuring $<2.5 \mathrm{~cm}$ to the highest risk value of $59 \%$ for those with poorly differentiated T1b-stage tumors measuring $>2.5 \mathrm{~cm}$ (Table 5). The risk of LNM was stratified as low risk $(<10 \%)$, moderate risk (10$30 \%$ ), and high risk (>30\%) based on the nomogram model.

\section{Discussion}

With the increasing application of endoscopic resection in T1-stage esophageal cancer, the ability to reliably predict nodal disease has become especially important to select the best treatment modality. In this study, a nomogram model was developed to predict LNM in patients with pT1-stage ESCC. Our nomogram model incorporated three clinicopathological factors, including tumor invasion depth, tumor differentiation, and tumor size, which were significantly associated with LNM. Based on the nomogram, a surgical treatment strategy was established according to the LNM risk stratification.

The depth of tumor invasion is probably the most important factor influencing LNM. The LNM rate of ESCC in T1a stage is $0-15.4 \%$ [3-11]. In our series, the incidence of LNM in T1a patients was 7.3\%, consistent with previous results. It is generally believed that the LNM rate of T1b ESCC is much higher than that of T1a ESCC, ranging from 15 to 51\% [3-11]. Most previous studies have reported an incidence of about $20 \%$, similar to the LNM rate of $22 \%$ for T1b tumors in our study. Some studies have divided the submucosa into three layers: sm1, sm2, and sm3 [18]. Nentiwch et al. [3] showed that tumors in all three layers had a higher and 
Table 1 The characteristics of the patients with pT1 ESCC

\begin{tabular}{|c|c|c|}
\hline Variables & Derivation, $n=223$ (\%) & Validation, $n=80(\%)$ \\
\hline Sex, male/female & $189 / 34$ & $69 / 11$ \\
\hline Age: median (range) & $59(42-77)$ & $62(42-75)$ \\
\hline \multicolumn{3}{|l|}{ Location } \\
\hline Upper & $13(5.8)$ & $7(8.8)$ \\
\hline Middle & $112(50.2)$ & $49(61.3)$ \\
\hline Lower & $98(44.0)$ & $24(30)$ \\
\hline \multicolumn{3}{|l|}{ Tumor number } \\
\hline Single & $200(89.7)$ & $71(88.8)$ \\
\hline Mutifocal & $23(10.3)$ & $9(11.3)$ \\
\hline Tumor size, cm: median (range) & $2.0 \mathrm{~cm}(0.3-7.0 \mathrm{~cm})$ & $2.0 \mathrm{~cm}(0.6-8.0 \mathrm{~cm})$ \\
\hline Harvested lymph nodes: median (range) & $19(0-85)$ & $19(3-76)$ \\
\hline \multicolumn{3}{|l|}{ Surgery } \\
\hline Sweet & $5(2.2)$ & 0 \\
\hline Ivor-Lewis & $52(23.3)$ & $3(3.75)$ \\
\hline Mckeown & $21(9.4)$ & $2(2.5)$ \\
\hline Minimally invasively esophagectomy & $145(65.0)$ & $75(93.7)$ \\
\hline \multicolumn{3}{|l|}{ cT stage } \\
\hline cT1a & $65(29.1)$ & $37(46.3)$ \\
\hline cT1b & $20(9.0)$ & $21(26.3)$ \\
\hline CT2 & $6(2.7)$ & $6(7.5)$ \\
\hline cT3 & $7(3.1)$ & $3(3.8)$ \\
\hline Unknown & $125(56.1)$ & $13(16.3)$ \\
\hline \multicolumn{3}{|l|}{ Differentiation } \\
\hline High-middle & $188(84.3)$ & $65(81.3)$ \\
\hline Low & $35(15.7)$ & $15(18.8)$ \\
\hline \multicolumn{3}{|l|}{ Depth of invasion } \\
\hline Mucosal epithelial & $34(15.2)$ & $8(10)$ \\
\hline Lamina propria mucosa & $4(1.3)$ & $3(3.8)$ \\
\hline Muscularis mucosae & $44(19.7)$ & $20(25)$ \\
\hline Submucosal & $141(63.7)$ & $49(61.3)$ \\
\hline \multicolumn{3}{|l|}{ Lymphovascular invasion } \\
\hline Not reported & $207(92.8)$ & $77(96.3)$ \\
\hline Reported & $16(7.2)$ & $3(3.75)$ \\
\hline \multicolumn{3}{|l|}{ Lymph node metastasis } \\
\hline No & $187(83.9)$ & $67(83.9)$ \\
\hline N1 & $30(13.5)$ & $9(13.5)$ \\
\hline N2 & $6(2.7)$ & $3(2.7)$ \\
\hline N3 & $0(0)$ & $1(1.25)$ \\
\hline
\end{tabular}

similar incidence of LNM [19]. However, Akutsu et al. [4] revealed that the metastasis and relapse rate increased with infiltration depth, at 16,35 , and $62 \%$ for tumors in $\mathrm{sm} 1, \mathrm{sm} 2$, and $\mathrm{sm} 3$, respectively. The current study also confirmed tissue differentiation as an independent risk factor, which had been revealed by many previous reports $[2,5,6,8]$. The risk of LNM increased with that of increasing tumor size [2.5]. The best cutoff value for tumor size was revealed as $2.5 \mathrm{~cm}$ in this study.

The current study also confirmed cervical, thoracic, and abdominal LNM in pT1-stage ESCC with bidirectional and skipping metastasis along the esophagus $[15$, 
Table 2 The mapping of LNM according to tumor location

\begin{tabular}{|c|c|c|c|c|}
\hline \multirow{2}{*}{$\begin{array}{l}\text { Station } \\
\text { name }\end{array}$} & \multirow[b]{2}{*}{ total } & \multirow[b]{2}{*}{ Upper (1) } & \multicolumn{2}{|c|}{ Location $^{\mathrm{a}}$} \\
\hline & & & & $\operatorname{er}(n=18)$ \\
\hline \multicolumn{5}{|l|}{ Cervical } \\
\hline 104 & 1 & & & 1 \\
\hline \multicolumn{5}{|l|}{ Thoracic } \\
\hline 105 & 2 & & & 2 \\
\hline 106recR & 13 & 1 & 7 & 5 \\
\hline 106recL & 6 & 1 & 5 & \\
\hline 108 & 3 & & 1 & 2 \\
\hline 107 & 1 & & & 1 \\
\hline $109 \mathrm{~L}$ & 1 & & 1 & \\
\hline 110 & 1 & & 1 & \\
\hline \multicolumn{5}{|l|}{ Abdominal } \\
\hline 1 & 2 & & 1 & 1 \\
\hline 2 & 5 & & & 5 \\
\hline 3 & 4 & & 2 & 2 \\
\hline 7 & 8 & & & 8 \\
\hline 8 & 1 & & & 1 \\
\hline
\end{tabular}

20, 21]. The most common LNMs were located at the recurrent laryngeal nerve and the left gastric artery [4, $22,23]$. The extent of lymph dissection in surgery should respect the LNM topography, even in early-stage ESCC.

Thus far, a few researchers have developed nomogram models to predict the risk of LNM in esophageal cancer $[6,11,24-26]$. For example, Zheng et al. [11] recently developed a nomogram for the prediction of LNM in early-stage ESCC patients. They included four items, namely depth of tumor invasion, tumor differentiation, tumor size, and lymphovascular invasion (LVI), and also validated the model with another case cohort. The rate of LVI in our study was $7.2 \%$ lower than that of $12.8 \%$ in a previous study [11] and another study of 20.5\% [5]. The low reporting rate may be the reason why LVI was not confirmed as an independent prediction factor in our study. An external validation was also performed using an independent case cohort from our cancer center.

Based on the nomogram model we constructed, LNM risk was stratified into different intensities starting from zero, for cases with well-differentiated T1a-stage tumors

Table 3 Risk factors for lymph node metastasis in deveriation cohort

\begin{tabular}{|c|c|c|c|c|c|c|}
\hline \multirow[t]{2}{*}{ Variables } & \multicolumn{2}{|c|}{$\underline{\text { LNM }}$} & \multirow{2}{*}{$\begin{array}{l}P \\
\text { value }\end{array}$} & \multicolumn{2}{|c|}{ Logistic regression analysis } & \multirow{2}{*}{$\begin{array}{l}P \\
\text { value }\end{array}$} \\
\hline & \multicolumn{2}{|c|}{ Negative (\%) Positive (\%) } & & OR & $95 \% \mathrm{Cl}$ & \\
\hline Male & $156(82.5)$ & $33(17.5)$ & & & & \\
\hline Female & $30(88.2)$ & $4(11.8)$ & & & & \\
\hline Age & & & 0.418 & - & - & - \\
\hline$<60$ years & $92(81.4)$ & $21(18.6)$ & & & & \\
\hline$>=60$ years & $94(85.5)$ & $16(14.5)$ & & & & \\
\hline Tumor location & & & 0.475 & - & - & - \\
\hline Upper & $12(92.3)$ & $1(7.7)$ & & & & \\
\hline Middle & $96(85.7)$ & $16(14.3)$ & & & & \\
\hline Lower & $77(80.2)$ & $19(19.8)$ & & & & \\
\hline Tumor number & & & 0.075 & - & - & - \\
\hline Single & $170(85.0)$ & $30(15.0)$ & & & & \\
\hline Mutifocal & $16(72.7)$ & $6(27.3)$ & & & & \\
\hline Tumor size & & & 0.029 & 2.420 & $1.070-5.473$ & 0.034 \\
\hline$<2.5 \mathrm{~cm}$ & $121(87.7)$ & $17(12.3)$ & & & & \\
\hline$>=2.5 \mathrm{~cm}$ & $65(76.5)$ & $20(23.5)$ & & & & \\
\hline Differentiation & & & 0.001 & 3.766 & $1.515-9.360$ & 0.004 \\
\hline High-middle & $164(87.2)$ & $24(12.8)$ & & & & \\
\hline Low & $22(62.9)$ & $13(37.1)$ & & & & \\
\hline Depth of invasion & & & 0.005 & 3.124 & $1.146-8.511$ & 0.026 \\
\hline T1a & $76(92.7)$ & $6(7.3)$ & & & & \\
\hline $\mathrm{T} 1 \mathrm{~b}$ & $111(78.7)$ & $30(21.3)$ & & & & \\
\hline Lymphovascular invasion & & & 0.001 & - & - & - \\
\hline Not reported & $178(86.0)$ & $29(14.0)$ & & & & \\
\hline Reported & $8(50.0)$ & $8(50.0)$ & & & & \\
\hline
\end{tabular}



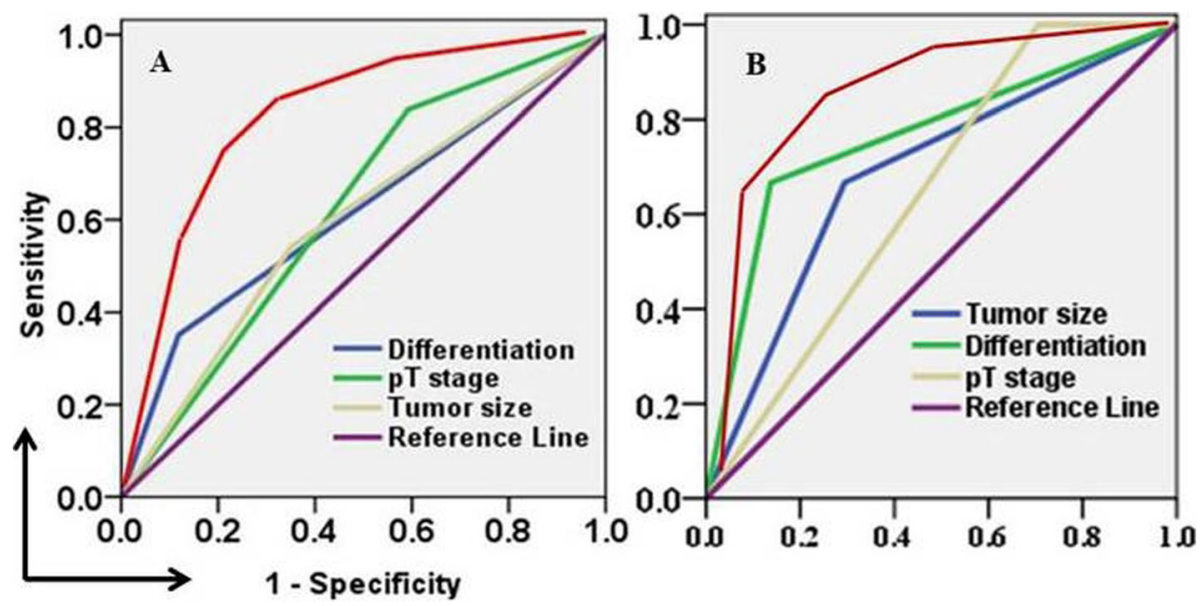

Fig. 2 The prediction ability of each risk factor and the combined model. a. Derivation cohort. Tumor differentiation in blue line: AUC 0.617, 95\% Cl 0.509-0.724 (Sensitivity 0.356, Specificity 0.870); pT stage in green line: $0.623,95 \%$ Cl 0.532-0.714 (Sensitivity 0.812, Specificity 0.413); Tumor size in brown line: $0.596,95 \%$ Cl 0.494-0.697 (Sensitivity 0.552, Specificity 0.645); Combined full model in red line: $0.81095 \%$ Cl $0.742-0.895$ (Sensitivity 0.821 , Specificity 0.652). b. Validation cohort. Tumor differentiation in green line: AUC $0.765,95 \%$ Cl 0.596-0.933 (Sensitivity 0.650, Specificity 0.830 ); PT stage in brown line: $0.647,95 \%$ Cl $0.498-0.796$ (Sensitivity 0.980, Specificity 0.312 ); Tumor size in blue line: $0.686,95 \%$ Cl $0.515-0.858$ (Sensitivity 0.650, Specificity 0.682); Combined full model in red line: 0.830, 95\% Cl 0.763-0.902 (Sensitivity 0.820, Specificity 0.760)

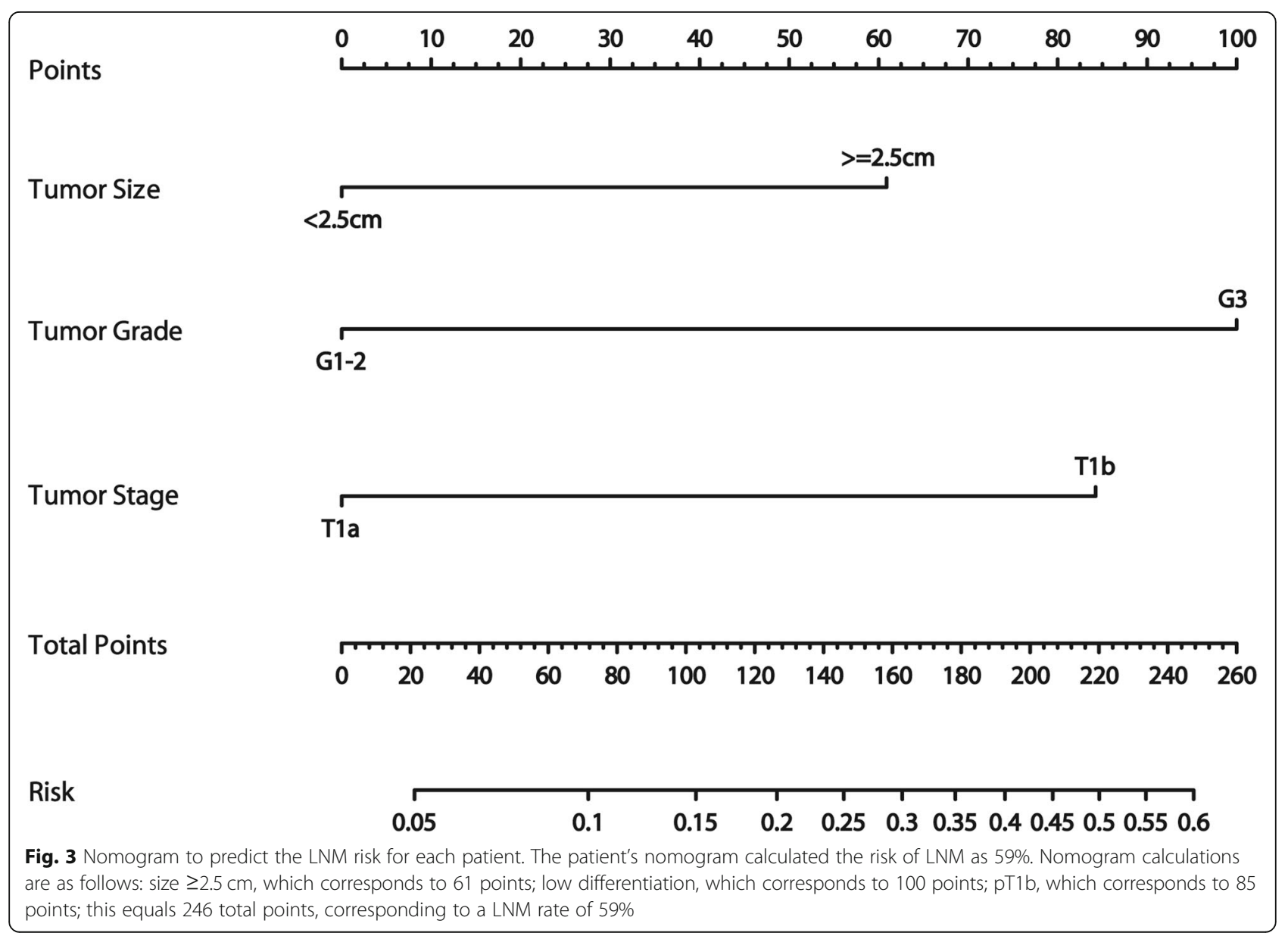


Table 4 Risk factors for lymph node metastasis in validation cohort

\begin{tabular}{|c|c|c|c|c|c|}
\hline \multirow[t]{2}{*}{ Variables } & \multicolumn{2}{|l|}{ LNM } & \multirow{2}{*}{$\begin{array}{l}P \\
\text { value }\end{array}$} & \multirow{2}{*}{$\begin{array}{l}\text { Logistic regression analysis } \\
\text { OR } 95 \% \mathrm{CI}\end{array}$} & \multirow{2}{*}{$\begin{array}{l}P \\
\text { value }\end{array}$} \\
\hline & Negative & & & & \\
\hline Male & $58(84.1)$ & $11(15.9)$ & & & \\
\hline Female & $9(81.8)$ & $2(18.2)$ & & & \\
\hline Age & & & 0.083 & - & - \\
\hline$<60$ years & $24(75.0)$ & $8(25.0)$ & & & \\
\hline$>=60$ years & $43(89.6)$ & $5(10.4)$ & & & \\
\hline Tumor location & & & 0.131 & - & - \\
\hline Upper & $6(85.7)$ & $1(14.3)$ & & & \\
\hline Middle & $38(77.6)$ & $11(22.2)$ & & & \\
\hline Lower & $23(95.8)$ & $1(4.2)$ & & & \\
\hline Tumor number & & & 0.450 & - & - \\
\hline Single & $60(84.5)$ & $11(15.5)$ & & & \\
\hline Mutifocal & $7(77.8)$ & $2(22.2)$ & & & \\
\hline Tumor size & & & 0.014 & $2.6741 .876-6.320$ & 0.008 \\
\hline$<2.5 \mathrm{~cm}$ & $46(85.2)$ & $4(14.8)$ & & & \\
\hline$>=2.5 \mathrm{~cm}$ & $21(80.8)$ & $9(19.2)$ & & & \\
\hline Differentiation & & & 0.008 & $3.9021 .843-10.354$ & 0.005 \\
\hline High-middle & $58(89.2)$ & $7(11.8)$ & & & \\
\hline Low & $9(60.0)$ & $6(40.0)$ & & & \\
\hline Depth of invasion & & & 0.012 & $3.2341 .230-8.543$ & 0.010 \\
\hline T1a & $30(96.8)$ & $1(3.2)$ & & & \\
\hline T1b & 37 (75.5) & $12(24.5)$ & & & \\
\hline
\end{tabular}

less than $2.5 \mathrm{~cm}$ in size, to the highest risk value, at $59 \%$, for those with poorly differentiated T1b-stage tumors bigger than $2.5 \mathrm{~cm}$ in size. The nomogram model can be used to help clinical decision-making to determine when endoscopic resection is adequate, or surgery is needed. In early-stage ESCC patients with metastatic nodes in preoperative evaluation, the standard treatment involves neoadjuvant therapy followed by esophagectomy. In patients without metastatic nodes, esophagectomy or endoscopic resection should be chosen as the primary

Table 5 Risk categories based on LNM risk model

\begin{tabular}{lll}
\hline Risk categories & Risk stratification & LNM risk \\
\hline Low risk & $T 1$ a, High/middle differentiated, $<2.5 \mathrm{~cm}$ & 0 \\
Low risk & T1a, High/middle differentiated, $>=2.5 \mathrm{~cm}$ & $8 \%$ \\
Moderate risk & $\mathrm{T} 1 \mathrm{a}$, Low differentiated, $<2.5 \mathrm{~cm}$ & $14 \%$ \\
Moderate risk & $\mathrm{T} 1 \mathrm{a}$, Low differentiated, $>=2.5 \mathrm{~cm}$ & $28 \%$ \\
Moderate risk & $\mathrm{T} 1 \mathrm{~b}$, High/middle differentiated, $<2.5 \mathrm{~cm}$ & $12 \%$ \\
Moderate risk & $\mathrm{T} 1 \mathrm{~b}$, High/middle differentiated, $>=2.5 \mathrm{~cm}$ & $24 \%$ \\
High risk & $\mathrm{T} 1 \mathrm{~b}$, Low differemtiated, $<2.5 \mathrm{~cm}$ & $36 \%$ \\
High risk & $\mathrm{T} 1 \mathrm{~b}$, Low differentiated, $>=2.5 \mathrm{~cm}$ & $59 \%$ \\
\hline
\end{tabular}

treatment, according to the risk stratification. If sufficient stratification information cannot be obtained, endoscopic resection should be considered as the first treatment option, allowing a subsequent decision on whether additional esophagectomy is needed. Clinical decisions also need to consider other clinical factors, including patient age, physical condition, willingness, socioeconomic factors, and the level of comprehensive knowledge of the surgeon or endoscopy physician.

The limitations of this study must be considered. First, the retrospective single institution study obviously may be accompanied by the potential risks of patient selection bias. Second, most patients underwent two-field lymphadenectomy without cervical lymph dissection. Third, the reported LVI rate is lower than that reported in the literature, which may have led to its exclusion as a risk factor in the nomogram model. Moreover, some studies have classified T1b tumors into three layers (sm1, sm2, and sm3). However, detailed data on classification were not obtained in the present study. In this group, insufficient lymph node dissection was performed in a few patients, which may underestimate the frequency of LNM. 


\section{Conclusions}

The incidence of LNM in patients with early-stage ESCC is high. With the increasing application of endoscopic resection, it is especially important to reliably predict nodal disease to select the best treatment modality. Based on a group of pT1-stage ESCC patients, a nomogram was developed to predict LNM risk. Overall, LNM risk is higher in T1b than in T1a tumors. However, patients with T1a tumors who exhibited poor differentiation or size $>2.5 \mathrm{~cm}$ had a higher LNM rate than those with T1b tumors without these other high-risk factors. This nomogram may be used to assist surgeons in deciding which patients should undergo esophagectomy and to select those patients with low LNM risk and curative endoscopic resection is sufficient.

\section{Abbreviations}

LNM: Lymph node metastasis; ESCC: Esophageal squamous cell carcinoma; OR: Odd ratio; Cl: Confidence interval

\section{Acknowledgements}

Not applicable.

\section{Authors' contributions}

$X D, Z Y$ and $H J$ contributed to the study conception and design. XD analyzed the data and wrote the manuscript. XS and JY collected the data and wrote manuscript. ZM, CC and PT interpreted the data. All authors have read and approved the final manuscript.

\section{Funding}

This article-processing charge (APC) was supported by Basic Research Grant from Tianjin Municipal Education Commission (2018KJ070). The funding bodies played no role in the design of the study and collection, analysis, and interpretation of data and in writing the manuscript.

\section{Availability of data and materials}

The data generated during the current study are not publicly available since they will contain patient data and the informed consent agreement does not include sharing data publicly. An anonymized form of the data could be made available from the corresponding author upon reasonable request.

\section{Declarations}

\section{Ethics approval and consent to participate}

The study was approved by the ethics committee of Tianjin Medical University Cancer Hospital, and written informed consent was obtained from all participants.

\section{Consent for publication}

Not applicable.

\section{Competing interests}

Not applicable.

Received: 18 October 2020 Accepted: 22 March 2021

Published online: 20 April 2021

\section{References}

1. Chen W, Zheng R, Zuo T, et al. National cancer incidence and mortality in China, 2012. Chin J Cancer Res. 2016;28:1-11.

2. Merkow RP, Bilimoria KY, Keswani RN, Chung J, Sherman KL, Knab LM, et al. Treatment trends, risk of lymph node metastasis, and outcomes for localized esophageal cancer. J Natl Cancer Inst. 2014;106(7):dju133. https:// doi.org/10.1093/jnci/dju133.

3. Nentwich MF, von Loga K, Reeh M, Uzunoglu FG, Marx A, Izbicki JR, et al. Depth of submucosal tumor infiltration and its relevance in lymphatic metastasis formation for T1b squamous cell and adenocarcinomas of the esophagus. J Gastrointest Surg. 2014;18(2):242-9; discussion 249. https://doi. org/10.1007/s11605-013-2367-2.

4. Akutsu Y, Uesato M, Shuto K, Kono T, Hoshino I, Horibe D, et al. The overall prevalence of metastasis in T1 esophageal squamous cell carcinoma: a retrospective analysis of 295 patients. Ann Surg. 2013;257(6):1032-8. https:// doi.org/10.1097/SLA.0b013e31827017fc.

5. Lee L, Ronellenfitsch U, Hofstetter WL, Darling G, Gaiser T, Lippert C, et al. Predicting lymph node metastases in early esophageal adenocarcinoma using a simple scoring system. J Am Coll Surg. 2013;217(2):191-9. https:// doi.org/10.1016/j.jamcollsurg.2013.03.015.

6. Gertler R, Stein HJ, Schuster T, Rondak IC, Höfler H, Feith M. Prevalence and topography of lymph node metastases in early esophageal and gastric cancer. Ann Surg. 2014;259(1):96-101. https://doi.org/10.1097/SLA 0000000000000239.

7. Tanaka T, Matono S, Mori N, Shirouzu K, Fujita H. T1 squamous cell carcinoma of the esophagus: long-term outcomes and prognostic factors after esophagectomy. Ann Surg Oncol. 2014;21(3):932-8. https://doi.org/1 0.1245/s10434-013-3372-0.

8. Dubecz A, Kern M, Solymosi N, Schweigert M, Stein HJ. Predictors of lymph node metastasis in surgically resected T1 Esophageal Cancer. Ann Thorac Surg. 2015;99(6):1879-85; discussion 1886. https://doi.org/10.1016/j.athora csur.2015.02.112.

9. Holscher $\mathrm{AH}$, Bollschweiler E, Schroder W, et al. Prognostic impact of upper, middle, and lower third mucosal or submucosal infiltration in early esophageal cancer. Ann Surg. 2011;254(5):802-7; discussion 807-808. https:// doi.org/10.1097/SLA.0b013e3182369128.

10. Duan $X$, Tang $P$, Shang $X$, et al. The prevalence of lymph node metastasis for pathological T1 esophageal cancer: a retrospective study of 143 cases. Surg Oncol. 2018;27(1):1-6. https://doi.org/10.1016/j.suronc.2017.11.002.

11. Zheng $H$, Tang $H$, Wang $H$, Fang $Y$, Shen $Y$, Feng $M$, et al. Nomogram to predict lymph node metastasis in patients with early oesophageal squamous cell carcinoma. British J Surg. 2018;105(11):1464-70. https://doi. org/10.1002/bjs.10882.

12. Thosani N, Singh H, Kapadia A, Ochi N, Lee JH, Ajani J, et al. Diagnostic accuracy of EUS in differentiating mucosal versus submucosal invasion of superficial esophageal cancers: a systematic review and meta-analysis. Gastrointest Endosc. 2012;75(2):242-53. https://doi.org/10.1016/j.gie.2011.09.016.

13. Pouw RE, Heldoorn N, Alvarez Herrero L, et al. Do we still need EUS in the workup of patients with early esophageal neoplasia? A retrospective analysis of 131 cases. Gastrointest Endosc. 2011;73(4):662-8. https://doi.org/1 0.1016/j.gie.2010.10.046.

14. Aoyama J, Kawakubo H, Mayanagi S, et al. Discrepancy Between the Clinical and Final Pathological Findings of Lymph Node Metastasis in Superficial Esophageal Cancer. Ann Surg Oncol. 2019

15. Akutsu $Y$, Kato $K$, lgaki $H$, et al. The prevalence of overall and initial lymph node metastases in clinical T1N0 thoracic Esophageal Cancer: from the results of JCOG0502, a prospective Multicenter study. Ann Surg. 2015.

16. Rice TW, Rusch W, Ishwaran H, Blackstone EH. Cancer of the esophagus and esophagogastric junction: data-driven staging for the seventh edition of the American joint committee on Cancer/International Union against Cancer Cancer staging manuals. Cancer. 2010;116(16):3763-73. https://doi. org/10.1002/cncr.25146.

17. Zhang $H$, Tang $P$, Miao $X$ et al. Does tumor size improve the accuracy of prognostic prediction in patients with esophageal squamous cell carcinoma after surgical resection? Oncotarget. 2016.

18. Ancona E, Rampado S, Cassaro M, Battaglia G, Ruol A, Castoro C, et al. Prediction of lymph node status in superficial esophageal carcinoma. Ann Surg Oncol. 2008;15(11):3278-88. https://doi.org/10.1245/s10434-008-0065-1.

19. Leers JM, DeMeester SR, Oezcelik $A$, et al. The prevalence of lymph node metastases in patients with $\mathrm{T} 1$ esophageal adenocarcinoma a retrospective review of esophagectomy specimens. Ann Surg. 2011;253(2):271-8. https:// doi.org/10.1097/SLA.0b013e3181fbad42.

20. Ma Z, Chen C, Duan $X$, et al. Characteristics and risk factors of lymph node metastasis in pN1 stage esophageal squamous cell carcinoma. Zhonghua Wai Ke Za Zhi. 2015;53:513-7.

21. Zhu Z, Yu W, Li H, Zhao K, Zhao W, Zhang Y, et al. Nodal skip metastasis is not a predictor of survival in thoracic esophageal squamous cell carcinoma. Ann Surg Oncol. 2013:20(9):3052-8. https://doi.org/10.1245/s10434-013-2 987-5.

22. Bollschweiler $E$, Baldus SE, Schroder W, et al. High rate of lymph-node metastasis in submucosal esophageal squamous-cell carcinomas and 
adenocarcinomas. Endoscopy. 2006;38(2):149-56. https://doi.org/10.1055/s-2 006-924993.

23. Endo M, Yoshino K, Kawano T, Nagai K, Inoue H. Clinicopathologic analysis of lymph node metastasis in surgically resected superficial cancer of the thoracic esophagus. Dis Esophagus. 2000;13(2):125-9. https://doi.org/10.104 6/j.1442-2050.2000.00100.x.

24. Semenkovich T, Yan Y, Subramanian M, et al. A Clinical Nomogram for Predicting Node-positive Disease in Esophageal Cancer. Ann Surg. 2019.

25. Newton A, Predina J, Xia L, et al. Surgical Management of Early-Stage Esophageal Adenocarcinoma Based on lymph node metastasis risk. Ann Surg Oncol. 2018;25(1):318-25. https://doi.org/10.1245/s10434-017-6238-z.

26. Weksler B, Kennedy K, Sullivan J. Using the National Cancer Database to create a scoring system that identifies patients with early-stage esophageal cancer at risk for nodal metastases. J Thorac Cardiovasc Surg. 2017;154(5): 1787-93. https://doi.org/10.1016/j.jtcvs.2017.07.036.

\section{Publisher's Note}

Springer Nature remains neutral with regard to jurisdictional claims in published maps and institutional affiliations.

Ready to submit your research? Choose BMC and benefit from:

- fast, convenient online submission

- thorough peer review by experienced researchers in your field

- rapid publication on acceptance

- support for research data, including large and complex data types

- gold Open Access which fosters wider collaboration and increased citations

- maximum visibility for your research: over $100 \mathrm{M}$ website views per year

At $\mathrm{BMC}$, research is always in progress.

Learn more biomedcentral.com/submissions 